\title{
Characterization and antibacterial application of biosynthesized silver nanoparticles using Piper retrofractum Vahl fruit extract as bioreductor
}

\author{
Suci Amaliyah ${ }^{1}$, Akhmad Sabarudin ${ }^{1,2^{*}}$ (D), Masruri Masruri ${ }^{1}$, Sutiman B. Sumitro ${ }^{3}$ \\ ${ }^{1}$ Department of Chemistry, Faculty of Science, Brawijaya University, Malang, Indonesia. \\ ${ }^{2}$ Division of Nanomaterial, Research Center for Advanced System and Material Technology, Brawijaya University, Malang, Indonesia. \\ ${ }^{3}$ Departement of Biology, Faculty of Science, Brawijaya University, Malang, Indonesia.
}

\begin{tabular}{l}
\hline ARTICLE INFO \\
\hline Received on: $11 / 05 / 2021$ \\
Accepted on: $18 / 11 / 2021$ \\
Available Online: $05 / 03 / 2022$
\end{tabular}

Key words:

Piper retrofractum Vahl, biosynthesis, silver, nanoparticles, antibacterial effect.

\begin{abstract}
A green method with a cost-effective and eco-friendly approach for synthesizing silver nanoparticles (AgNPs) using Piper retrofractum Vahl fruit extract as a bioreductor was investigated in this study. The effect of extract concentrations, reaction times, temperatures, and $\mathrm{pHs}$ under ultrasonication and stirring procedures on AgNPs formation was also studied. The characteristic of biosynthesized AgNPs was analyzed using Ultraviolet-Visible Spectrophotometry, Fourier Transform Infra-Red, Field Emission Scanning Electron Microscopy (FESEM)-Energy Dispersive Spectroscopy, X-Ray Diffraction, and Transmission Electron Microscopy. The result showed that the smaller size of AgNPs was formed using extract concentration $100 \%$ under alkaline conditions for 60 minutes and $60^{\circ} \mathrm{C}$ of reaction time and temperature. The distribution size of AgNPs synthesized by stirring procedure has a more uniform size than the ultrasonication procedure. The morphology of AgNPs was a spherical shape, and the most extensive distribution size was within 1-5 nm. The biosynthesized AgNPs also showed antibacterial activity. From FESEM photographs, it was found that AgNPs cause changes in bacterial cell morphology, indicating that these nanoparticles penetrate the bacterial cell membrane, causing bacterial cell death. The combination of AgNPs with extract and antibiotic was more effective than AgNPs, extract, or antibiotic alone.
\end{abstract}

\section{INTRODUCTION}

Silver nanoparticles (AgNPs) received special attention from researchers (Firdhouse and Lalitha, 2015; Yasir et al., 2017) as they have applications in various fields. The widespread application of AgNPs has also led to increased environmental and biological safety in their production, especially in the medical field. The general methods of AgNP synthesis are a chemical and physical approach that is expensive and potentially harmful to

\footnotetext{
"Corresponding Author

Akhmad Sabarudin, Department of Chemistry, Faculty of Science, Brawijaya University, Malang, Indonesia; Division of Nanomaterial, Research Center for Advanced System and Material Technology, Brawijaya University, Malang, Indonesia.E-mail: sabarjpn@gmail.com; sabarjpn@ub.ac.id
}

the environment (Makarov et al., 2014; Yusuf, 2020). A greener method through biosynthesis was an alternative method to minimize their disadvantages.

Biosynthesis approaches for AgNP synthesis have been reported using fungi (Azmath et al., 2016; Kanaujiya et al., 2019; Shahzad et al., 2019), bacteria (Hamouda et al., 2019), and plants (Krithiga et al., 2015; Masum et al., 2019; Tripathy et al., 2019). Plant extracts are considered as a better approach because they are free from toxic chemicals as byproducts (Krithiga et al., 2015), can act as a metal ion bio-reductor, and provide natural capping agents due to the presence of functional groups such as phenols, terpenoids, carboxylic acids, aldehydes, enzymes, amides, and flavones (Masum et al., 2019). In addition, the use of plant extracts can be more beneficial than using microorganisms because it is free from the threat of microorganism contamination and can reduce the cost of isolating microorganisms and culture 
media (Krithiga et al., 2015; Masum et al., 2019). Recent studies reported that extract of Citrus sinensis (Dutta et al., 2020), hawthorn berries (Długosz et al., 2020), Tridax procumbens (Rani et al., 2019), Lysiloma acapulcensis (Garibo et al., 2020), and Sida retusa (Sooraj et al., 2020) have successfully used as natural reagents in AgNP synthesis. The synthesized nanoparticles using these plant extracts showed different shapes and sizes depending on the species of plants.

In this study, we used Piper retrofractum Vahl fruit extract as a natural reagent for the biosynthesis of AgNPs. Piper retrofractum Vahl, known as cabe jawa or cabe jamu in Indonesia, was a member of the family Piperaceae generally used as traditional medicine (Panphut et al., 2020; Tang et al., 2019). Our previous study has reported the use of $P$. retrofractum Vahl fruit extract as a natural reagent in the synthesis of copper nanoparticles (Amaliyah et al., 2020). However, the use of this fruit extract for the biosynthesis of AgNPs has not been reported elsewhere. Piper retrofractum Vahl contains some compounds such as flavonoids, tannins, alkaloids, and steroids/terpenoids (Mansoi et al., 2016), which can act as reducing as well as stabilizing agents in the formation of AgNPs. These compounds are expected to produce a controlled morphology and size of AgNPs.

The main challenges faced in the synthesis of nanoparticles are controlling the size and shape of the nanosized particles and achieving monodispersity (Chatterjee et al., 2020). So, in this study, some factors that affect the production of AgNPs, such as extract concentration, reaction time, temperature, $\mathrm{pH}$ (Shah et al., 2015), and reaction process by stirring and ultrasonication (Sumitomo et al., 2018), were investigated. Generally, the smaller sizes of nanoparticles were obtained in higher extract concentration (Khalil et al., 2014), higher temperatures (Jain and Mehata, 2017), and higher $\mathrm{pH}$ (Anigol et al., 2017). Increasing reaction time enhances the conversion of silver ions to nanoparticles, leading to smaller particle size (Pandey et al., 2012). Ultrasonication and stirring process affect the dispersion of resulting nanoparticles. It was reported that ultrasonic irradiation dispersion was more efficient than stirring (Sumitomo et al., 2018) so that it may produce more uniform nanoparticles. The objective of this investigation was to obtain the proper methods in controlled-size nanoparticle formation. Furthermore, the characteristics of synthesized AgNPs were analyzed using Ultraviolet-Visible Spectrophotometry (UV-Vis), Fourier Transform Infra-Red (FTIR), Field Emission Scanning Electron Microscopy-Energy Dispersive Spectroscopy (FESEM-EDS), X-Ray Diffraction (XRD), and Transmission Electron Microscopy (TEM). The agar well diffusion method was applied to analyze the antimicrobial properties of synthesized AgNPs to Escherichia coli and Staphylococcus aureus bacteria.

\section{MATERIIALS AND METHODS}

\section{Materials and instrumentation}

Piper retrofractum Vahl fruits were obtained from Sumenep District, Madura Island, East Java, Indonesia. Silver nitrate used as a silver ion precursor was purchased from Sigma Aldrich, Singapore. Escherichia coli (Gram-negative bacteria) and $S$. aureus (Gram-positive bacteria) were used as exposed bacteria in antimicrobial activity tests. UV-Vis (Shimadzu UV-Vis
1601 series), FTIR (Shimadzu 8400s), FESEM-EDS (FEI-Quanta FEG 650), XRD (PANalytical Japan), and TEM (TEM HT7700) were used for the characterization of AgNPs. The synthesis of AgNPs was processed in a hotplate stirrer (CORNING PC-620D) and ultrasonicator bath (DELTA Ultrasonic Cleaner DC150H).

\section{Aqueous extraction of $\boldsymbol{P}$. retrofractum Vahl fruits}

Piper retrofractum Vahl fruits were washed thoroughly using tap water and dried at $50^{\circ} \mathrm{C}$ for 5 days (Chansang et al., 2005). The extract was further prepared by modifying the previous method (Devasenan et al., 2016). One hundred g of dried fruits was then coarsely ground, mixed with $500 \mathrm{ml}$ of water, and then heated with stirring at $60^{\circ} \mathrm{C}$ for 30 minutes. The mixtures were then filtered using filter paper and centrifuged. The filtrates $(P$. retrofractum Vahl fruit extract) were separated and collected to be utilized as a natural reagent for the biosynthesis of AgNPs.

\section{Biosynthesis of AgNPs}

The biosynthesis procedure of AgNPs modified the previous methods (Ibrahim, 2015; Krithiga et al., 2015). The reaction process was conducted in two techniques by stirring process using a hotplate stirrer and the ultrasonication process using the ultrasonicator bath. The reaction mixture was prepared by mixing $0.1 \mathrm{M}$ silver nitrate $\left(\mathrm{AgNO}_{3}\right)$ aqueous solution with $P$. retrofractum fruit extract with a volume ratio of $1: 2$. This composition was used in all of the reaction processes. The reaction mixtures were incubated using a dark bottle to avoid photoactivation of $\mathrm{AgNO}_{3}$. The effect of extract concentration was investigated by varying $P$. retrofractum Vahl extract concentrations $(20 \%, 40 \%, 60 \%, 80 \%$, and $100 \%)$, and the reaction was carried out at $60^{\circ} \mathrm{C}$ for 60 minutes. An extract concentration of $100 \%$ was used for further experiments. The effect of reaction time was evaluated by incubating the reaction mixture at $60^{\circ} \mathrm{C}$ for $15,30,45$, and 60 minutes. The temperature effect on AgNP biosynthesis was studied by incubating the reaction mixture at $25^{\circ} \mathrm{C}, 35^{\circ} \mathrm{C}, 60^{\circ} \mathrm{C}$, and $80^{\circ} \mathrm{C}$ for 60 minutes. The $\mathrm{pH}$ effect was studied by adjusting the $\mathrm{pH}$ of the reaction mixture to $\mathrm{pH} 4,6,8$, and 10 by the addition of $\mathrm{NaOH} / \mathrm{HCl} 0.1 \mathrm{M}$. The reaction mixture was also incubated at $60^{\circ} \mathrm{C}$ for 60 minutes. Then, all synthesized AgNPs were separated by centrifugation at 2,500 rpm for 15 minutes and washed using distilled water and ethanol.

\section{Characterization of the biosynthesized AgNPs}

The biosynthesized AgNPs characterization was performed using UV-Vis, FTIR, XRD, FESEM-EDS, and TEM (Amaliyah et al., 2020). The UV-Vis (Shimadzu UV-Vis 1601 series) was used to monitor the formation. AgNPs suspension was dispersed in solvents, and the spectra were recorded as a function of wavelength from 200 to $800 \mathrm{~nm}$. The role of extract in the biosynthesis of AgNPs was analyzed by FTIR. The dried AgNPs were ground with $\mathrm{KBr}$ pellets and analyzed by FTIR spectrophotometer (Shimadzu 8400s). The spectrum was recorded at $4,000-400 \mathrm{~cm}^{-1}$. The size and morphology of AgNPs were assessed by FESEM-EDS and TEM. For FESEM-EDS analysis, AgNPs were sprinkled on top of the stub with double-sided carbon tape without sputter coating. FESEM (FEI-Quanta FEG 650) was operated at $15 \mathrm{kV}$ with a high vacuum mode. For TEM, a drop 
of AgNPs sample dispersed in ethanol was loaded on a carboncoated copper grid, and it was allowed to dry at room temperature. TEM (TEM HT7700) was operated at $100 \mathrm{kV}$. The micrograph and selected area (electron) diffraction were recorded. XRdiffractogram was obtained using XRD (PANalytical Japan) with $\mathrm{Cu}$ K-Alpha1.54 $\AA$ and generator settings $30 \mathrm{~mA}, 40 \mathrm{kV}$.

\section{Antimicrobial assay of synthesized AgNPs}

An antimicrobial assay of the resulting AgNPs was conducted using the agar well diffusion method (Rajeshkumar and Malarkodi, 2014) against Gram-positive (S. aureus) and Gramnegative bacteria (E. coli). Each bacterium was inoculated into a nutrient broth medium for 18 hours. Agar wells were prepared by perforating the nutrient agar medium using a sterile cork borer. The wells were filled with $20 \mu 1$ samples then incubated at $37^{\circ} \mathrm{C}$ for 24 hours. Chloramphenicol and water were used as a positive and negative control, respectively. The inhibition zone was determined by measuring the diameter of the clear area around the wells. The experiments were carried out in three replicates.

\section{RESULTS AND DISCUSSION}

\section{Biosynthesis of AgNPs}

Biosynthesis of AgNPs using plant extracts has been widely reported (Benakashani et al., 2016; Hemlata et al., 2020; Krithiga et al., 2015; Masum et al., 2019; Pirtarighat et al., 2019). However, finding nanoparticles with precise physical, chemical, and biological characteristics remains a challenge in nanoscience researches (Masum et al., 2019). This study used P. retrofractum Vahl fruit extract to synthesize AgNPs. The phytochemical test showed the presence of the phenolic compound in this fruit extract (Amaliyah et al., 2020). This plant was also reported that contain amides (Muharini et al., 2015), phenylpropanoids (Luyen et al., 2014), and piperidine alkaloids (Kim et al., 2011). Although the exact mechanism of AgNP formation by plant extract was unclear, these compounds were expected to play a pivotal role in the AgNPs formation process. The interaction between the compounds in plant extracts with silver ions $\left(\mathrm{Ag}^{+}\right)$caused bioreduction of silver nitrate and the formation of AgNPs $\left(\mathrm{Ag}^{0}\right)$. The hydroxyl groups and negatively charged groups such as carboxylate have a high propensity to attaching the $\mathrm{Ag}^{+}$surface. These compounds can act as bioreducing and capping/stabilizing agents in forming AgNPs (Pirtarighat et al., 2019). The mechanism of AgNP formation is illustrated in Figure 1.

The preliminary evidence of AgNP formation was the color change of the reaction mixture in the reaction process. This proof can be seen from the color change of the starting material ( $\mathrm{AgNO}_{3}$ solution) from colorless to blackish brown after reacting with $P$. retrofractum fruit extract, indicating the reduction of $\mathrm{Ag}^{+}$ to $\mathrm{Ag}^{0}$ in $\mathrm{AgNO}_{3}$ solution. The formation of AgNPs was also confirmed by analysis using a UV-Vis spectrophotometer. The spectrum of UV-Vis of AgNPs was different from the P. retrofractum Vahl fruit extract (Fig. 2). It showed that the absorption maxima at $476 \mathrm{~nm}$ showed the surface plasmon resonance characteristic of AgNPs. This result was in line with previous reports. The surface plasmon resonance characteristic of AgNPs was found at 400-500 nm (Alsamhary, 2020; Ashraf et al., 2016).
Effect of extract concentration, reaction time, temperature, and $\mathrm{pH}$ in ultrasonication and stirring process of AgNP biosynthesis

Effect of extract concentration during the formation of AgNPs was observed by mixing P. retrofractum Vahl fruit extract $(20 \%, 40 \%, 60 \%, 80 \%$, and $100 \%)$ with a constant concentration of silver nitrate $(0.1 \mathrm{M})$. The darker blackish brown was formed with increasing the extract concentration indicating the more synthesized AgNPs. A darker blackish brown was also observed in the ultrasonication process compared to the stirring process. The surface plasmon resonance, both stirring and ultrasonication procedure of synthesized AgNPs, was observed in all extract concentration variations, except concentration $20 \%$ in ultrasonication process (Fig. $2 \mathrm{a}$ and $\mathrm{b}$ and Table 1). The surface plasmon resonance of AgNPs showed the maximum peak intensity in extract concentration $100 \%$ with a shorter wavelength. It indicated that extract concentration $100 \%$ resulted in more synthesized AgNPs and smaller AgNP size than other concentrations. A previous study reported that the surface plasmon resonance peak shifted to a lower wavelength when the particle size became smaller (Ider et al., 2017). At higher concentrations,

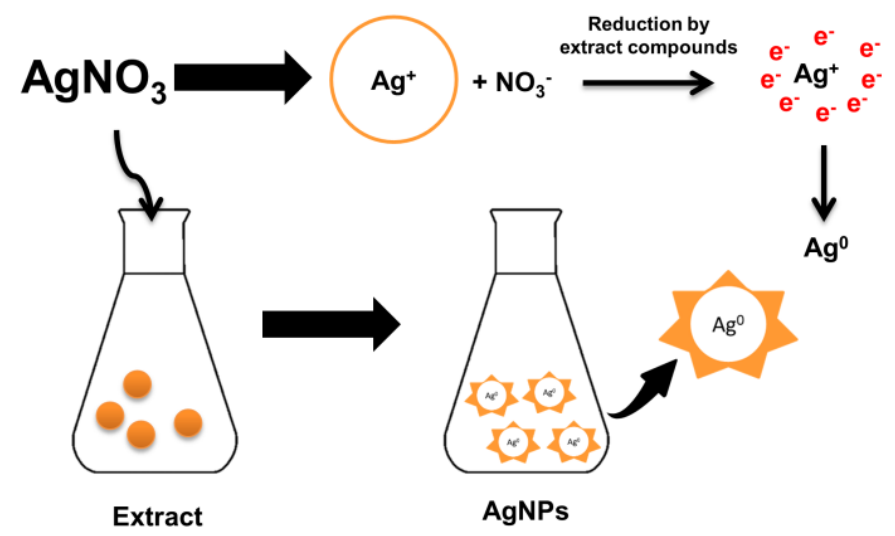

Figure 1. Mechanism of AgNPs formation by P. retrofractum Vahl extract.

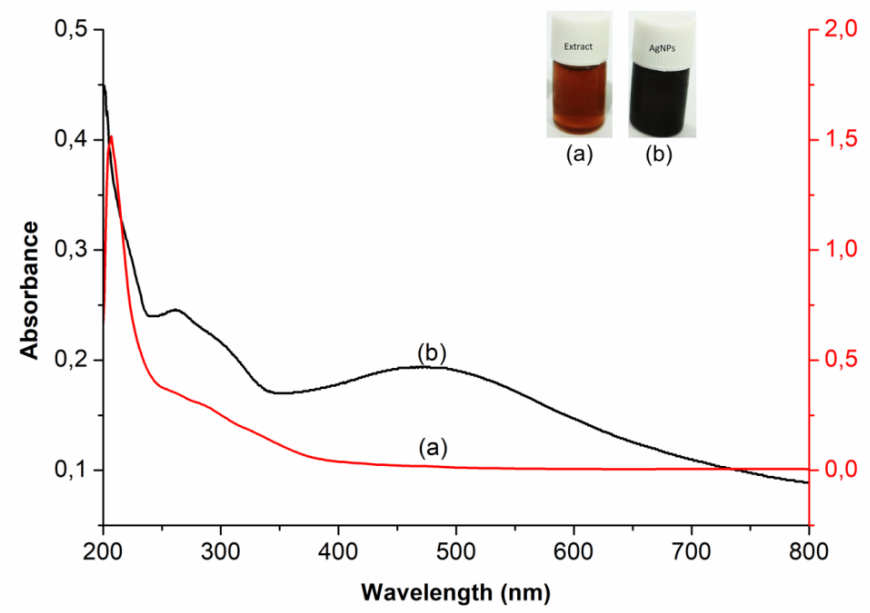

Figure 2. UV-visible spectrum of $P$. retrofractum extract (a) and biosynthesized AgNPs (b). 
Table 1. The wavelength $(\mathrm{nm})$ of the surface plasmon resonance of AgNPs synthesized by ultrasonication and stirring procedures.

\begin{tabular}{|c|c|c|c|}
\hline \multirow{2}{*}{$\begin{array}{l}\text { Parameters } \\
\text { AgNPs synthesized by ultrasonication procedure }\end{array}$} & & \multicolumn{2}{|c|}{ Surface plasmon resonance wavelength $(\mathrm{nm})$} \\
\hline & & AgNPs synthesized by & \\
\hline \multirow{5}{*}{ Extract concentration $(\%)$} & 20 & - & 474 \\
\hline & 40 & 478 & 481 \\
\hline & 60 & 479 & 496 \\
\hline & 80 & 483 & 476 \\
\hline & 100 & 476 & 471 \\
\hline \multirow{4}{*}{ Time (minutes) } & 15 & 458 & 511 \\
\hline & 30 & 497 & 474 \\
\hline & 45 & 483 & 478 \\
\hline & 60 & 476 & 471 \\
\hline \multirow{4}{*}{ Temperature $\left({ }^{\circ} \mathrm{C}\right)$} & 25 & - & 329 \\
\hline & 45 & 483 & 330 \\
\hline & 60 & 476 & 471 \\
\hline & 80 & 495 & 494 \\
\hline \multirow{4}{*}{$\mathrm{pH}$} & 4 & 450 & 448 \\
\hline & 6 & 456 & 451 \\
\hline & 8 & 478 & 513 \\
\hline & 10 & 349 & 343 \\
\hline
\end{tabular}

the extract contains compounds or reducing agents and molecular stabilizing agents in larger quantities. As a result, the reaction rate will be higher, and the size of nanoparticles will be smaller (Bezares et al., 2018; Khalil et al., 2014).

Reaction time has also affected the formation of AgNPs. The darker blackish brown was formed with a longer reaction time. Figure 3B-F shows the UV-visible spectrum of AgNPs synthesized by ultrasonication and stirring procedure with the variation reaction time. The intensity of absorbance increased along with increasing the reaction time, indicating the enhancement of the silver ions reduction to silver atoms. Surface plasmon resonance of AgNPs shifted to a lower wavelength with a longer reaction time, indicating the smaller particle size (Table 1). This result was similar to the previous report. The early stage of reaction time shows a low conversion of silver ions to metallic AgNPs. Prolonging the reaction time up to certain minutes leads to the large conversion of silver ions to AgNPs and cluster formation. However, further increase in the reaction time probably cause some aggregation of AgNPs that may cause the increase of nanoparticles size (Pandey et al., 2012).

Effect of temperature in AgNPs formation was observed after 60 minutes reaction time. A previous study reported that smaller particle size was produced at higher temperature (Jain and Mehata, 2017). Figure 3C-G show the UV-Vis spectrum of AgNPs at different temperatures through ultrasonication and stirring. In the stirring procedure, surface plasmon resonance of AgNPs synthesized at $25^{\circ} \mathrm{C}$ and $45^{\circ} \mathrm{C}$ showed the wavelength at 329 and $330 \mathrm{~nm}$, respectively. These results were different from other surface plasmon resonances. Nevertheless, Balavandy et al. (2014) reported that the surface plasmon resonance of AgNPs was around $300 \mathrm{~nm}$.
In contrast to the previous report (Jain and Mehata, 2017), surface plasmon resonance in this study shifted to a longer wavelength at a higher temperature $\left(80^{\circ} \mathrm{C}\right)$. It indicates the larger particle size of AgNPs, probably due to the agglomeration of AgNPs. Moreover, high temperatures can denature extract compounds, lead to lesser availability of compounds in the system, and slow the reaction rate, leading to larger nanoparticles formation.

Figure 3D-H shows the effect of $\mathrm{pH}$ on the formation of AgNPs. The acidity was an essential parameter in the formation of AgNPs. It affects the extract involved in the formation of AgNPs. $\mathrm{pH}$ changes the electrostatic states of substances or biomolecules in plant extract, which is involved in reducing and stabilizing AgNPs, affecting the shape and size of the AgNPs (Khalil et al., 2014). In this study, the lower surface plasmon resonance wavelength was obtained at $\mathrm{pH} 4$ and 10 compared to $\mathrm{pH} 6$ and 8 conditions. This result suggests that the smaller particle size of AgNPs was formed at extreme acid and base conditions. Surface plasmon resonance (Table 1) showed that $\mathrm{pH} 10$ had the lowest surface plasmon resonance, exhibiting the optimum $\mathrm{pH}$ condition of AgNP formation. This result was in good agreement with the previous report (Balavandy et al., 2014). At the base condition, more functional groups available for silver binding facilitated a higher number of AgNPs to bind and subsequently form a large number of nanoparticles with smaller diameters (Veerasamy et al., 2011).

Most of the surface plasmon resonance of AgNPs synthesized using stirring procedure was shorter than ultrasonication procedure. It indicates that the stirring technique produced a smaller size of AgNPs compared to the ultrasonication procedure. This result was in contrast with a previous study that uses Fenugreek seed extract to synthesize AgNPs. The previous 

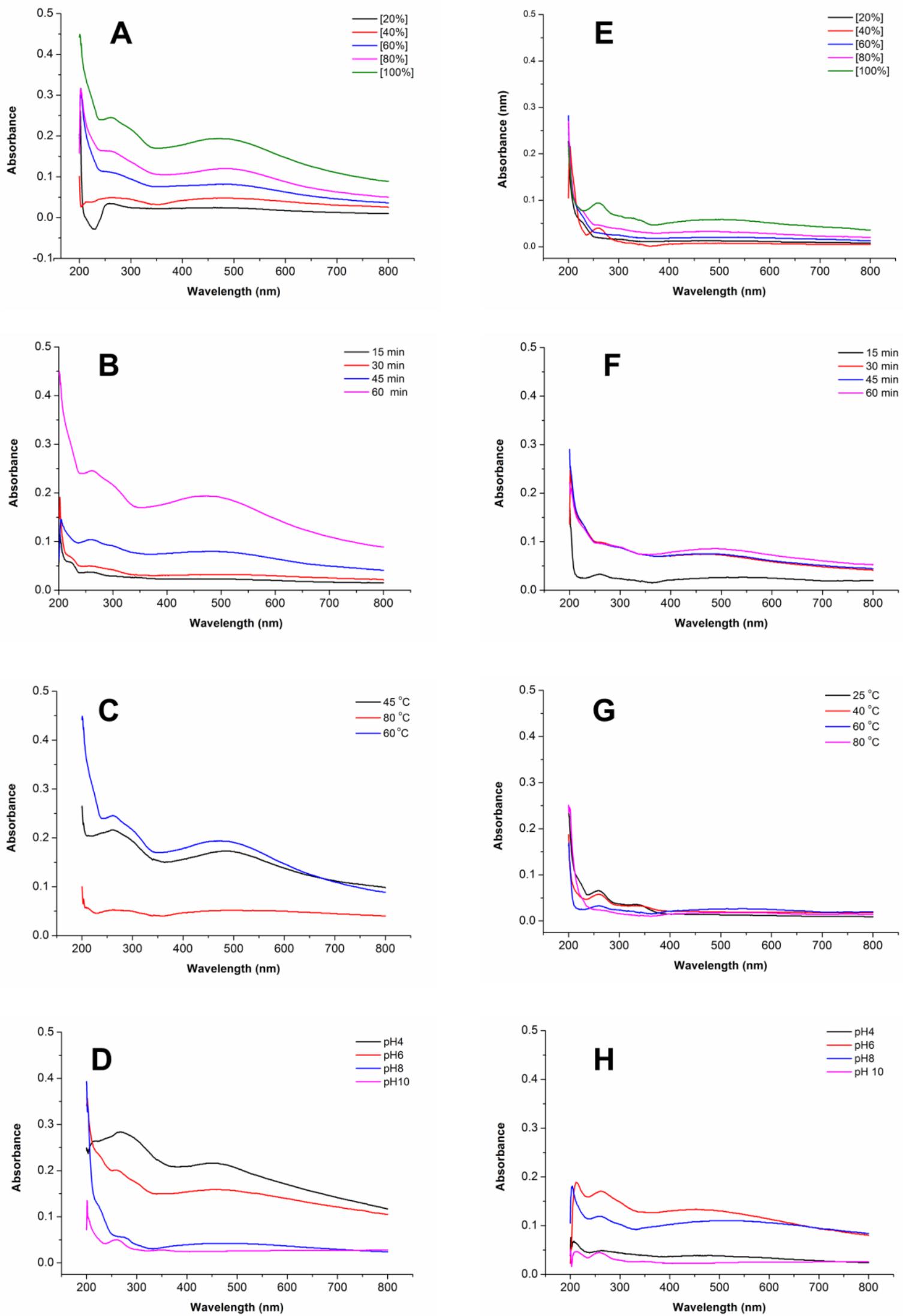

Figure 3. Comparison of UV-visible spectra of the synthesized AgNPs by ultrasonication (left) and stirring (right) procedures at various parameters: extract concentrations $(\mathrm{A}-\mathrm{E})$; reaction times $(\mathrm{B}-\mathrm{F})$; temperatures $(\mathrm{C}-\mathrm{G})$; and $\mathrm{pHs}(\mathrm{D}-\mathrm{H})$. 
research reported that AgNPs synthesized using ultrasonication were more uniform and smaller in size than the stirring procedure (Deshmukh et al., 2019). The difference between our results and the previous study may be due to the different compounds involved in the AgNP formation process. The compounds of $P$. retrofractum extract may be sensitive to ultrasound waves so that they can cause damage to the compounds. As we know, some organic compounds can be degraded by ultrasonic waves (Bremner et al., 2011).

\section{Characterization of AgNPs}

The shape, size, and morphology of AgNPs were characterized by FESEM and TEM analysis. FESEM photograph showed that the AgNPs were spherical and aggregated (Fig. 4). EDS analysis showed the elemental composition of synthesized AgNPs both quantitatively and qualitatively. The EDS spectrum (Fig. 5) of synthesized AgNPs showed the presence of silver $(\mathrm{Ag})$, carbon $(\mathrm{C})$, oxygen $(\mathrm{O})$, chlorine $(\mathrm{Cl})$, aluminum $(\mathrm{Al})$, sulfur (S), and phosphorus (P). The strong signal of Ag showed the highest percentage of silver, indicating the purity of AgNPs. Other elements may be derived from $P$. retrofractum Vahl extract as starting material involved in stabilizing AgNPs.

Reaction conditions: temperature, $60^{\circ} \mathrm{C}$; extract concentration, $100 \%$; reaction time, 60 minutes; by ultrasonication process. Magnification: $50,000 \times$

Figure 6 shows the TEM photograph of AgNPs synthesized using $P$. retrofractum Vahl extract by ultrasonication and stirring procedure. The shape of AgNPs synthesized by ultrasonication and stirring procedure predominates with spherical morphology and ranges from 1 to 40 and 1 to $25 \mathrm{~nm}$, respectively. The highest distribution of AgNPs sizes by ultrasonication ranges from 11 to $15 \mathrm{~nm}$, while the stirring process ranges from 1 to $5 \mathrm{~nm}$. Both of AgNPs synthesized by ultrasonication and stirring process are in aggregated form. AgNPs synthesized using a stirring procedure were more aggregated, smaller, and uniform in size distribution than the ultrasonication procedure. This result is likely due to the high-frequency oscillations of ultrasonic waves that can break agglomerated nanoparticles into separate particles (Li et al., 2012) so that their size distribution is within a wide range.
Most of the AgNPs synthesized using plant extract were spherical. The morphology of AgNPs in this study was similar to AgNPs synthesized using Andean blackberry (Kumar et al., 2017) and Tectona grandis (Rautela et al., 2019). It was likely due to the functional groups of phytochemical compounds present in $P$. retrofractum fruit extract similar to both plants (Kumar et al., 2017; Rautela et al., 2019).

The role of the extract active compounds in the formation and stabilization of AgNPs was evaluated by FT-IR analysis before and after the reaction with silver ions. The spectra were recorded in the region $400-4,000 \mathrm{~cm}^{-1}$ to determine the specific absorption of AgNPs and the functional groups of extract compounds involved in forming AgNPs. The spectra of AgNPs (Fig. 7) showed the new absorption band in the fingerprint area at around 535 and $702 \mathrm{~cm}^{-1}$, which was expected as the characteristic bands of Ag-O-H (Wang and Andrews, 2005). Some absorption

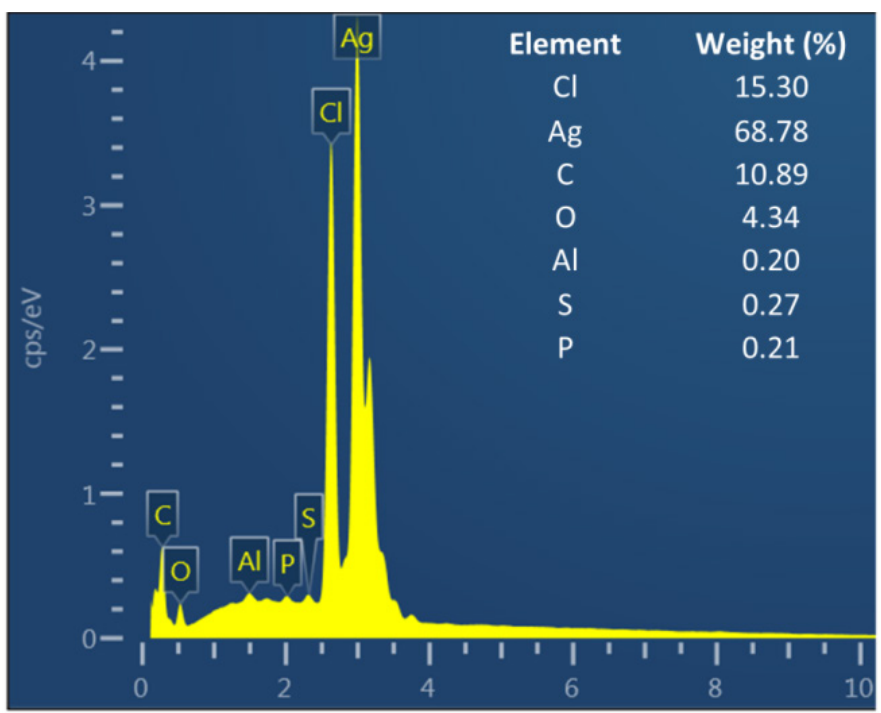

Figure 5. EDS profile of AgNPs synthesized using P. retrofractum Vahl fruit extract (conditions were similar as in Fig. 4).


Figure 4. FESEM photograph of AgNPs synthesized using P. retrofractum Vahl extract at an acceleration voltage of $10 \mathrm{kV}$ (left) and $5 \mathrm{kV}$ (right). 

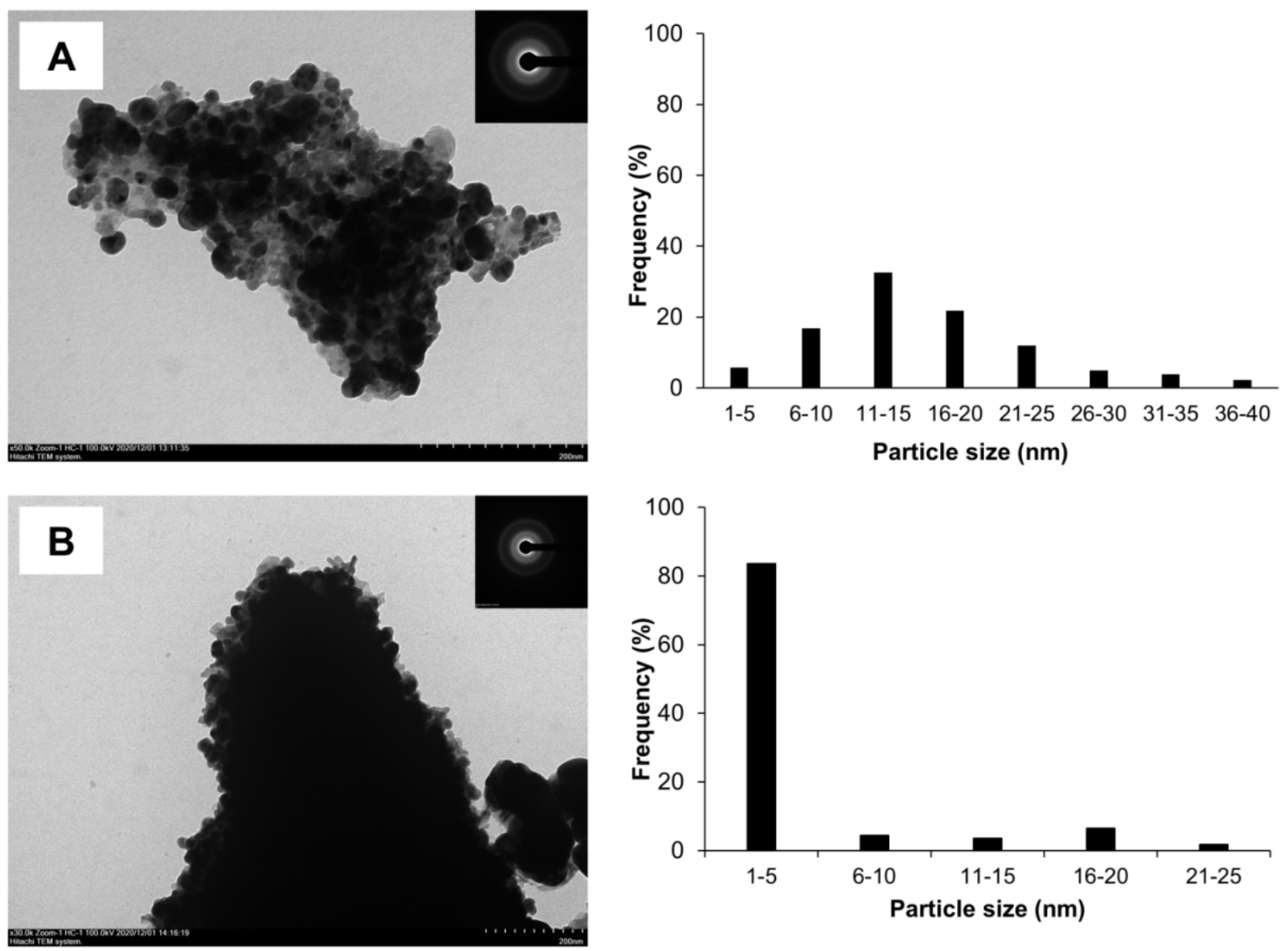

Figure 6. TEM photograph, selected area diffraction (SAED) pattern (inset), and size distribution of AgNPs synthesized by ultrasonication (A) and stirring process (B) (reaction condition: temperature, $60^{\circ} \mathrm{C}$; extract concentration, $100 \%$; reaction time, 60 minutes)

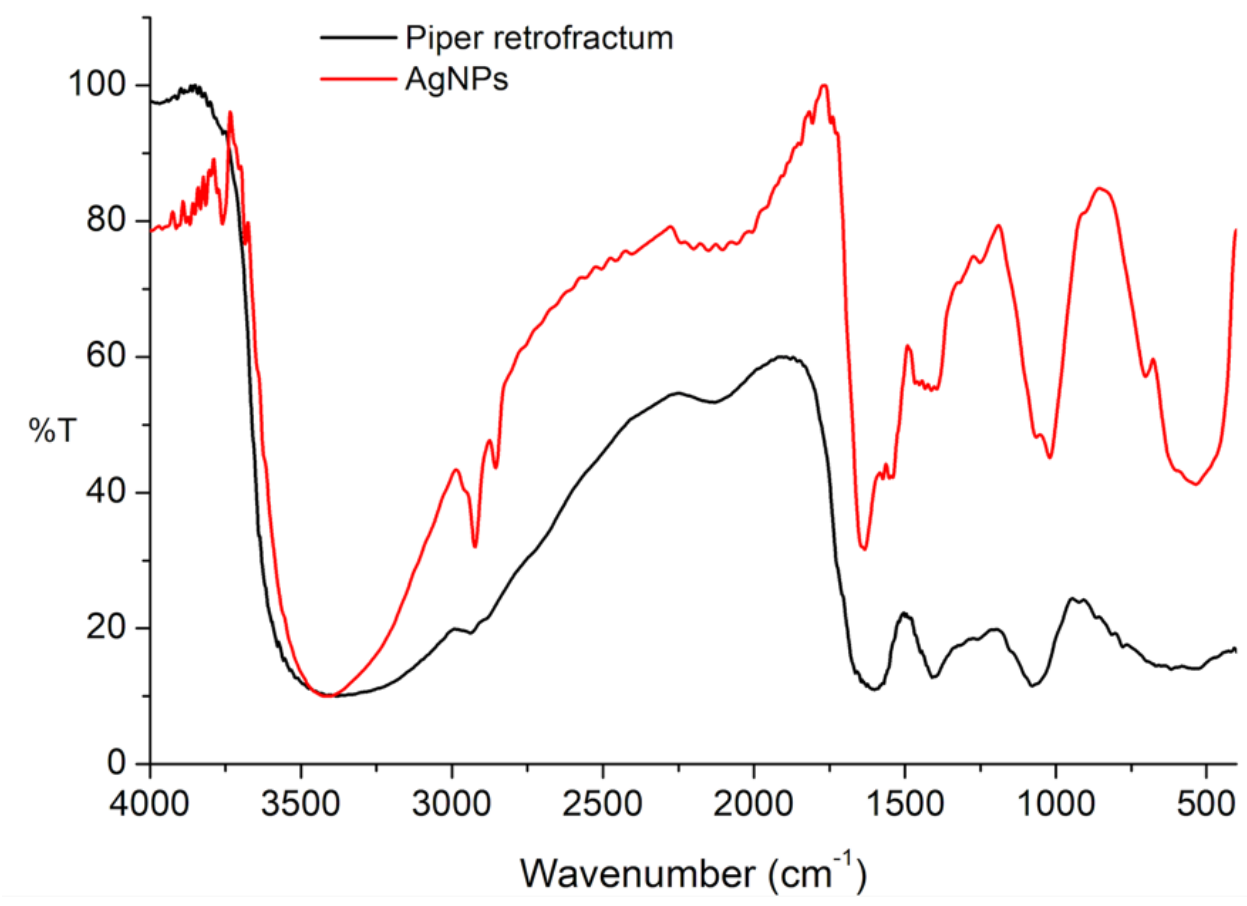

Figure 7. FTIR spectra of AgNPs and P. retrofractum Vahl extract. 


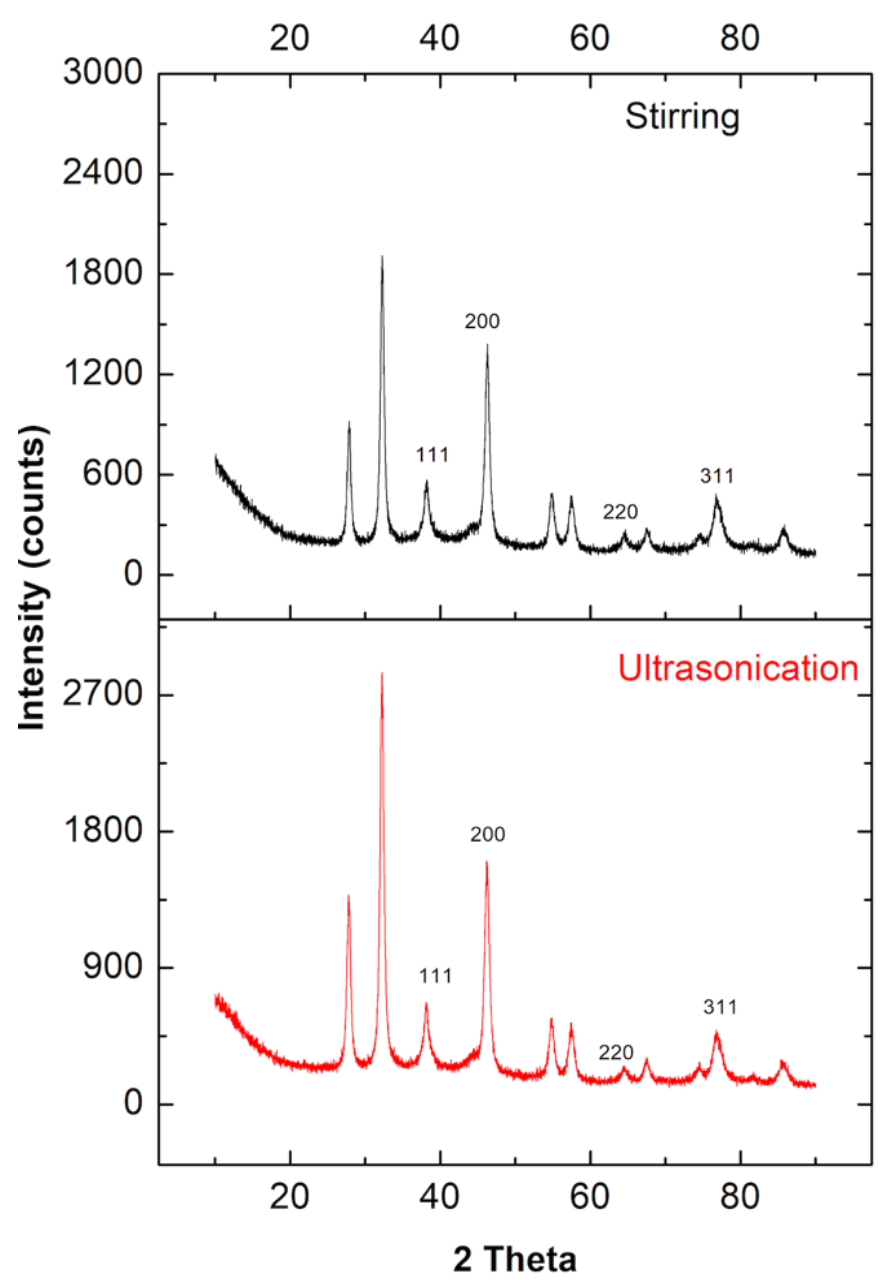

Figure 8. XR-diffractogram of AgNPs synthesized by stirring and ultrasonication procedures (reaction condition: temperature, $60^{\circ} \mathrm{C}$; extract concentration, $100 \%$; reaction time, 60 minutes).

bands of AgNPs did not have significant differences compared to the extract, showing functional groups of active compounds. The band around $3,425 \mathrm{~cm}^{-1}$ was assigned to $\mathrm{O}-\mathrm{H}$ and $\mathrm{N}-\mathrm{H}$ groups absorptions. The absorption band at $2,924 \mathrm{~cm}^{-1}$ is related to the $-\mathrm{C}-\mathrm{H}$ group. Vibration band at 1,603 and $1,376 \mathrm{~cm}^{-1}$ was relevant to $\mathrm{C}=\mathrm{C}$ and $\mathrm{C}-\mathrm{N}$-like amine or $\mathrm{C}-\mathrm{O}-$ like phenol groups, respectively. The absorption band at $1,068 \mathrm{~cm}^{-1}$ indicated the vibration band of $\mathrm{C}-\mathrm{O}$ (Balashanmugam and Kalaichelvan, 2015; Duman et al., 2016). It indicated that the active compounds of the extract were involved in the formation and stabilization of AgNPs. This finding was in good agreement with the result reported so far (Khan et al., 2016), which showed that the spectrum of AgNPs synthesized using extracts has two absorption areas: the functional group area for absorption of extract compounds and fingerprint area for metal absorption.

XRD analysis was used to confirm the formation and structure of AgNPs. Figure 8 shows the XR-diffractogram of biosynthesized AgNPs by stirring and ultrasonication. The pattern of both stirring and ultrasonication showed 11 peaks. The peaks at $2 \theta=38.16^{\circ}, 46.19^{\circ}, 64.47^{\circ}$, and $76.73^{\circ}$ correspond to the 111 , 200, 220, and $311 \mathrm{fcc}$ lattice planes, respectively, confirming the existence of AgNPs. Our findings were in line with previous studies (Anandalakshmi et al., 2016; Kumar et al., 2017; Srirangam and Rao, 2017). The extra peaks at $2 \theta=27.79^{\circ}, 32.26^{\circ}, 54.77^{\circ}, 57.41^{\circ}$, $67.51^{\circ}, 74.51^{\circ}$, and $85.59^{\circ}$ probably were caused by the organic phase as capping/stabilizing agent on the surface of AgNPs. The crystalline nature of biosynthesized AgNPs was determined by calculating the crystallinity index from the XRD spectrum. The crystallinity index of biosynthesized AgNPs by ultrasonication and stirring process was $65.7 \%$ and $61.25 \%$, respectively. Both indicated that the biosynthesized AgNPs were crystalline. AgNPs synthesized by ultrasonication were more crystalline than the stirring process.

In this study, the crystalline nature of AgNPs was in contrast with the SAED pattern. The SAED pattern showed the diffuse rings indicating the amorph phase of AgNPs. The difference between XRD and SAED results was probably because the material also contains amorphic organic material.

\section{Antibacterial Activity of AgNPs}

In this study, the antibacterial effects of biosynthesized AgNPs by ultrasonication and stirring procedures were studied against E. coli and $S$. aureus. The inhibition zones of this investigation are shown in Figure 9 and Table 2.

The biosynthesized AgNPs in this study showed a lower antibacterial effect than the antibiotic (chloramphenicol). The antibacterial properties of AgNPs synthesized by ultrasonication showed a better result against $S$. aureus bacteria. This result was in good agreement with the previous reports (Alavi et al., 2019; Hasanzadeh et al., 2021). Meanwhile, AgNPs synthesized by the stirring procedure showed a better effect on E. coli bacteria, as also shown by another report (Alavi and Karimi, 2020). The different effect of AgNPs against Gram-positive and negative bacteria was probably due to the different characteristics of the membrane structure of Gram-positive and negative bacteria and the nature and size of the AgNPs. AgNPs synthesized by ultrasonication had a larger size with higher crystallinity (Fig. 6) than AgNPs synthesized by stirring procedure, exhibiting a lower antibacterial effect. The biological activities of nanoparticles were determined not only by their chemical form but also by their morphology. Smaller nanoparticle sizes demonstrate higher antibacterial activities than larger particles (Losasso et al., 2014; Qing et al., 2018). The type, size, shape of nanoparticles, green source, and bacterial species should be considered as the main factors influencing antibacterial activity (Alavi and Karimi, 2020). These factors may also affect the antibacterial mechanism of both bacteria, as shown in Figure 10.

Although the antibacterial properties of AgNPs in this study showed lower activity than the antibiotic (chloramphenicol), they showed better effect against $S$. aureus when combined with extract and antibiotic. It indicated that the combined effect was better than AgNPs, the extract, or the antibiotic alone. In the case of $E$. coli, the combination of AgNPs with extract and antibiotic exhibited an almost similar inhibition zone compared to the antibiotic itself. Hari et al. (2014) reported that the combination effect of AgNPschloramphenicol showed a better antibacterial effect against $E$. coli and $S$. aureus bacteria. This finding was probably due to the combination of AgNPs with antibiotics showing a synergistic effect that can increase the antibacterial activity. The synergistic effect in this study only occurred against $S$. aureus. It may indicate that the 
a
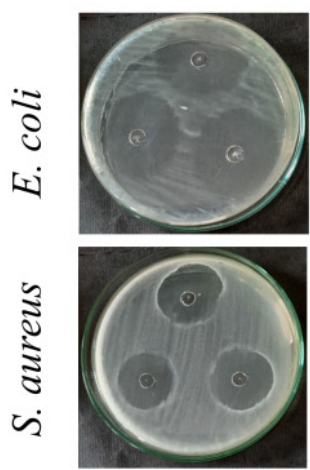

$\mathrm{b}$
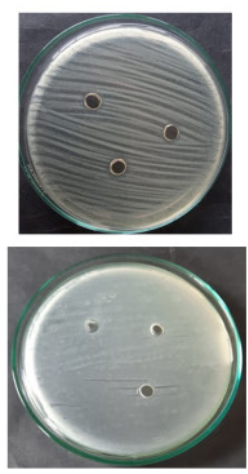

c
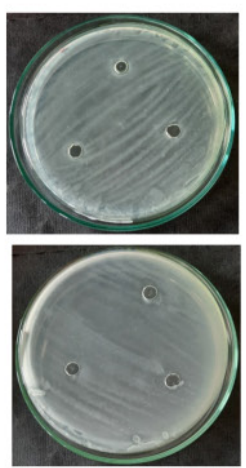

$\mathrm{d}$
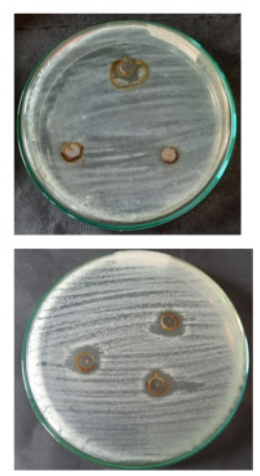

$\mathrm{e}$
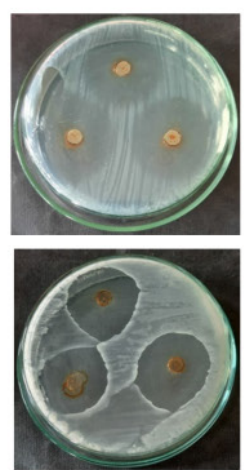

$\mathrm{f}$
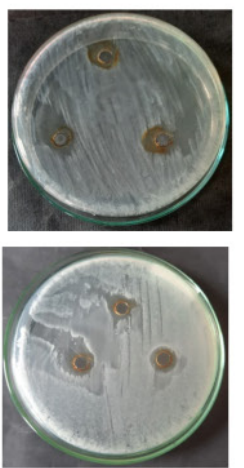

g
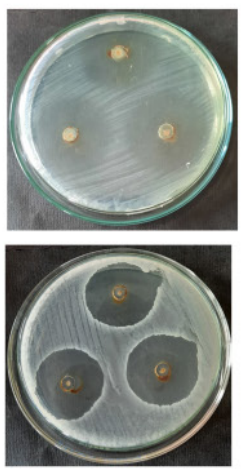

Figure 9. Inhibition zones of chloramphenicol (a); distilled water (b); Piper retrofractum fruit extract (c); AgNPs synthesized by ultrasonication (d); AgNPs synthesized by ultrasonication combined with extract and chloramphenicol (e); AgNPs synthesized by stirring (f); AgNPs synthesized by stirring combined with extract and chloramphenicol (g) against E. coli and S. aureus.

Table 2. Inhibition zone of AgNPs against E. coli and S. aureus.

\begin{tabular}{ccc}
\hline Samples & \multicolumn{2}{c}{ Inhibition zone (mm) } \\
\cline { 2 - 3 } & Escherichia coli & Staphylococcus aureus \\
\hline Positive control (chloramphenicol $0.01 \mathrm{~g} / \mathrm{ml})$ & 32.58 & 20.87 \\
Negative control (water) & - & - \\
Piper retrofractum fruit extract & - & 6.69 \\
$\mathrm{AgNPs}(10 \mu \mathrm{l} / \mathrm{ml})$ synthesized by ultrasonication & 4.92 & 27.18 \\
$\mathrm{AgNPs}(10 \mu \mathrm{l} / \mathrm{ml})$ synthesized by ultrasonication + extract + & 31.19 & 7.40 \\
chloramphenicol & 9.16 & 28.06 \\
$\mathrm{AgNPs}(10 \mu \mathrm{l} / \mathrm{ml})$ synthesized by stirring & 29.22 & \\
\hline
\end{tabular}
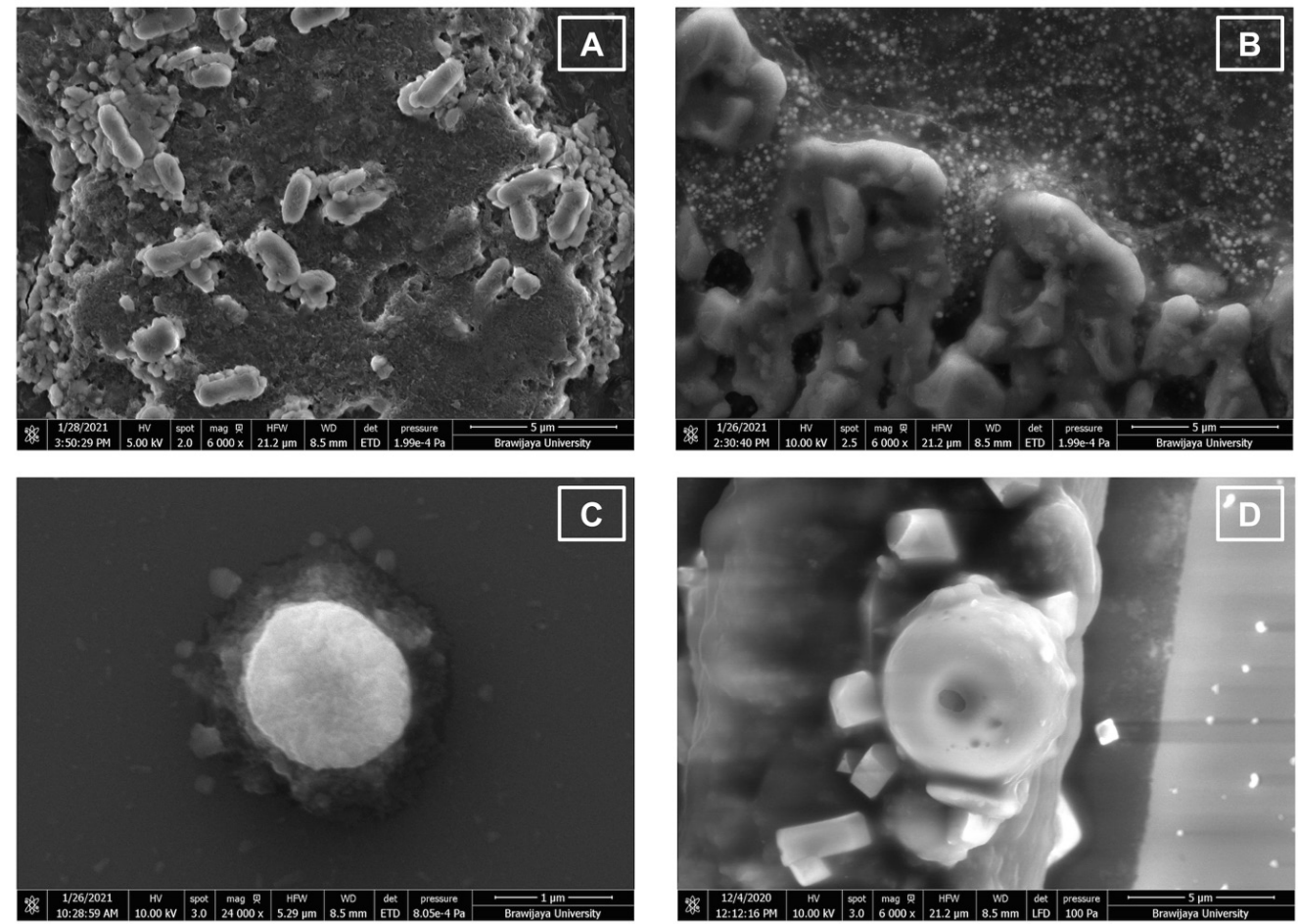

Figure 10. FESEM photograph of bacterial cells of (A) untreated-E. coli, 6,000× magnification; (B) Escherichia coli treated with AgNPs, 6,000× magnification; (C) untreated S. aureus, 24,000× magnification; and (D) Staphylococcus aureus treated with AgNPs, 6,000× magnification. 
biosynthesized AgNPs in this study were selective against grampositive bacteria.

The antibacterial properties of AgNPs were due to their capability to affect the bacterial cell. Their nanoscale size and large ratio of surface area to the volume were related to their efficacy. AgNPs can penetrate the bacterial cell walls, change the cell membrane structure, and trigger cell death (Yin et al., 2020). FESEM photographs showed that AgNPs could cause changes in bacterial cell morphology (Fig. 10). AgNPs may enter the bacterial cell membrane and make E. coli and $S$. aureus cells to become swell and shrink (Fig. 10B-D), causing bacterial cell death. This result was similar to another study on AgNPs antibacterial activity toward $P$. aeruginosa as gram-negative bacteria. This work stated that the shrinking cell wall proved the interaction of AgNPs with a part of the bacteria as the antibacterial mechanism of metal nanoparticles (Alavi et al., 2019).

\section{CONCLUSION}

AgNPs were biosynthesized using $P$. retrofractum fruit extract as the bioreductor and capping agents. The characterization using UV-Vis, FTIR, XRD, FESEM-EDS, and TEM analysis showed that the AgNPs were successfully formed. The smaller AgNPs were obtained at alkaline conditions using 100\% extract concentration with a reaction temperature of $60^{\circ} \mathrm{C}$ and a reaction time of 60 minutes. AgNPs synthesized by stirring procedure have more uniform size distribution, smaller particle size, and higher antibacterial effect than ultrasonication procedure. Biosynthesized AgNPs were spheric with the highest size distribution within 1-5 $\mathrm{nm}$ and showed antibacterial activity against $E$. coli and $S$. aureus.

\section{ACKNOWLEDGMENTS}

The authors would like to thank the Ministry of Research and Technology of the Republic of Indonesia for partial support through Penelitian Dasar 2021 No: 108/SP2H/LT/DRPM/2021 for the funding in this work.

\section{AUTHOR CONTRIBUTIONS}

All authors made substantial contributions to conception and design, acquisition of data, or analysis and interpretation of data; took part in drafting the article or revising it critically for important intellectual content; agreed to submit to the current journal; gave final approval of the version to be published; and agree to be accountable for all aspects of the work. All the authors are eligible to be an author as per the international committee of medical journal editors (ICMJE) requirements/guidelines.

\section{CONFLICT OF INTERESTS}

The authors declare no conflict of interest

\section{ETHICAL APPROVALS}

This study does not involve experiments on animals or human subjects.

\section{DATA AVAILABILITY}

All data generated and analyzed are included within this research article.

\section{PUBLISHER'S NOTE}

This journal remains neutral with regard to jurisdictional claims in published institutional affiliation.

\section{REFERENCES}

Alavi M, Karimi N. Hemoglobin self-assembly and antibacterial activities of bio-modified $\mathrm{Ag}-\mathrm{MgO}$ nanocomposites by different concentrations of Artemisia haussknechtii and Protoparmeliopsis muralis extracts. Int J Biol Macromol, 2020; 152:1174-85.

Alavi M, Karimi N, Valadbeigi T. Antibacterial, antibiofilm, antiquorum sensing, antimotility, and antioxidant activities of green fabricated $\mathrm{Ag}, \mathrm{Cu}, \mathrm{TiO} 2, \mathrm{ZnO}$, and $\mathrm{Fe} 3 \mathrm{O} 4 \mathrm{NPs}$ via protoparmeliopsis muralis lichen aqueous extract against multi-drug-resistant bacteria. ACS Biomater Sci Eng, 2019; 5(9):4228-43.

Alsamhary KI. Eco-friendly synthesis of silver nanoparticles by Bacillus subtilis and their antibacterial activity. Saudi J Biol Sci, 2020; 27(8):2185-91.

Amaliyah S, Pangesti DP, Masruri M, Sabarudin A, Sumitro SB. Green synthesis and characterization of copper nanoparticles using Piper retrofractum Vahl extract as bioreductor and capping agent. Heliyon, 2020; 6(8):e04636.

Anandalakshmi K, Venugobal J, Ramasamy V. Characterization of silver nanoparticles by green synthesis method using Pedalium murex leaf extract and their antibacterial activity. Appl Nanosci, 2016; 6(3):399-408.

Anigol LB, Charantimath JS, Gurubasavaraj PM. Effect of concentration and ph on the size of silver nanoparticles synthesized by green chemistry. Org Med Chem Int J, 2017; 3:1-5.

Ashraf JM, Ansari MA, Khan HM, Alzohairy MA, Choi I. Green synthesis of silver nanoparticles and characterization of their inhibitory effects on AGEs formation using biophysical techniques. Sci Rep, 2016; 6:20414.

Azmath P, Baker S, Rakshith D, Satish S. Mycosynthesis of silver nanoparticles bearing antibacterial activity. Saudi Pharm J, 2016; 24(2):140-6.

Balashanmugam P, Kalaichelvan PT. Biosynthesis characterization of silver nanoparticles using Cassia roxburghii DC. aqueous extract, and coated on cotton cloth for effective antibacterial activity. Int J Nanomedicine, 2015; 10(Suppl 1):87.

Balavandy SK, Shameli K, Biak DR, Abidin ZZ. Stirring time effect of silver nanoparticles prepared in glutathione mediated by green method. Chem Cent J, 2014; 8(1):11.

Benakashani F, Allafchian AR, Jalali SA. Biosynthesis of silver nanoparticles using Capparis spinosa L. leaf extract and their antibacterial activity. Karbala Int J Mod Sci, 2016; 2(4):251-8.

Bezares B, Jaña Y, Cottet L, Castillo A. Effect of $\mathrm{pH}$ and leaf extract concentration of Pittosporum undulatum on gold nanoparticles synthesis. Materi Exp, 2018; 8(5):450-6.

Bremner DH, Burgess AE, Chand R. The chemistry of ultrasonic degradation of organic compounds. Curr Org Chem, 2011;15(2): 168-77.

Chansang U, Zahiri NS, Bansiddhi J, Boonruad T, Thongsrirak P, Mingmuang J, Benjapong N, Mulla MS. Mosquito larvicidal activity of aqueous extracts of long pepper (Piper retrofractum Vahl) from Thailand. J Vector Ecol, 2005; 30(2):95.

Chatterjee A, Kwatra N, Abraham J. Nanoparticles fabrication by plant extracts. In: Thajuddin N and Mathew S, ed(s). Phytonanotechnology: challenges and prospects, Elsevier, Amsterdam, The Netherlands, 143 p, 2020.

Devasenan S, Beevi NH, Jayanthi S. Synthesis and characterization of Copper Nanoparticles using leaf extract of Andrographis paniculata and their antimicrobial activities. Int J ChemTech Res, 2016; 9(04):725-30

Deshmukh AR, Gupta A, Kim BS. Ultrasound assisted green synthesis of silver and iron oxide nanoparticles using fenugreek seed extract and their enhanced antibacterial and antioxidant activities. BioMed Res Intl, 2019; 2019: 1714358. 
Długosz O, Chwastowski J, Banach M. Hawthorn berries extract for the green synthesis of copper and silver nanoparticles. Chem Papers, 2020; 74(1):239-52.

Duman F, Ocsoy I, Kup FO. Chamomile flower extractdirected $\mathrm{CuO}$ nanoparticle formation for its antioxidant and DNA cleavage properties. Mater Sci Eng C Mater Biol Appl, 2016; 60:333-8; doi:10.1016/j.msec.2015.11.052

Dutta T, Chattopadhyay AP, Ghosh NN, Khatua S, Acharya K, Kundu S, Mitra D, Das M. Biogenic silver nanoparticle synthesis and stabilization for apoptotic activity; insights from experimental and theoretical studies. Chem Papers, 2020; 74:4089-101.

Firdhouse MJ, Lalitha P. Biosynthesis of silver nanoparticles and its applications. J Nanotechnol, 2015; 2015: 829526.

Garibo D, Borbón-Nuñez HA, de León JND, García Mendoza E, Estrada I, Toledano-Magaña Y, Tiznado H, Ovalle-Marroquin M, Soto-Ramos AG, Blanco A, Rodríguez JA, Romo OA, Chávez-Almazán LA, Susarrey-Arce A. Green synthesis of silver nanoparticles using Lysiloma acapulcensis exhibit high-antimicrobial activity. Sci Rep, 2020; 10(1):1-11.

Hamouda RA, Hussein MH, Abo-Elmagd RA, Bawazir SS. Synthesis and biological characterization of silver nanoparticles derived from the cyanobacterium Oscillatoria limnetica. Sci Rep, 2019; 9(1):1-17.

Hari N, Thomas TK, Nair AJ. Comparative study on the synergistic action of differentially synthesized silver nanoparticles with $\beta$-cephem antibiotics and chloramphenicol. J Nanoscience, 2014; 2014: 201482 .

Hasanzadeh A, Gholipour B, Rostamnia S, Eftekhari A, Tanomand A, Valizadeh K A, Khaksar S, Khalilov R. Biosynthesis of AgNPs onto the urea-based periodic mesoporous organosilica (AgxNPs/ Ur-PMO) for antibacterial and cell viability assay. J Colloid Interface Sci, 2021; 585:676-83.

Hemlata, Meena PR, Singh AP, Tejavath KK. Biosynthesis of silver nanoparticles using cucumis prophetarum aqueous leaf extract and their antibacterial and antiproliferative activity against cancer cell lines. ACS Omega, 2020; 5(10):5520-8.

Ibrahim HM. Green synthesis and characterization of silver nanoparticles using banana peel extract and their antimicrobial activity against representative microorganisms. J Radiat Res Appl Sci, 2015; $8(3): 265-75$.

Ider M, Abderrafi K, Eddahbi A, Ouaskit S, Kassiba A. Silver metallic nanoparticles with surface plasmon resonance: synthesis and characterizations. J Cluster Sci, 2017; 28(3):1051-69.

Jain S, Mehata MS. Medicinal plant leaf extract and pure flavonoid mediated green synthesis of silver nanoparticles and their enhanced antibacterial property. Sci Rep, 2017; 7(1):15867.

Kanaujiya D, Kumar V, Dwivedi SK, Prasad G. Photobiosynthesis of silver nanoparticle using extract of Aspergillus flavus CR500: its characterization, antifungal activity and mechanism against Sclerotium rolfsii and Rhizoctonia solani. J Cluster Sci, 2019; 31: 1041-50.

Khalil MM, Ismail EH, El-Baghdady KZ, Mohamed D. Green synthesis of silver nanoparticles using olive leaf extract and its antibacterial activity. Arab J Chem, 2014; 7(6):1131-9.

Khan FA, Zahoor M, Jalal A, Rahman AU. Green synthesis of silver nanoparticles by using Ziziphus nummularia leaves aqueous extract and their biological activities. J Nanomater, 2016; 2016: 8026843

Kim KJ, Lee MS, Jo K, Hwang JK. Piperidine alkaloids from Piper retrofractum Vahl. Protect against high-fat diet-induced obesity by regulating lipid metabolism and activating AMP-activated protein kinase. Biochem Biophys Res Commun, 2011; 411(1):219-25.

Krithiga N, Rajalakshmi A, Jayachitra A. Green synthesis of silver nanoparticles using leaf extracts of Clitoria ternatea and Solanum nigrum and study of its antibacterial effect against common nosocomial pathogens. J Nanoscience, 2015; 2015: 928204.
Kumar B, Smita K, Cumbal L, Debut A. Green synthesis of silver nanoparticles using Andean blackberry fruit extract. Saudi J Biol Sci, 2017; 24(1):45-50.

Li Y, Xie HQ, Wang JF, Yu W. Study on the preparation and properties of copper nanoparticles and their nanofluids. In: Advanced materials research, Trans Tech Publications Ltd, Freienbach, Switzerland, pp 606-9, vol. 399, 2012.

Losasso C, Belluco S, Cibin V, Zavagnin P, Mičetić I, Gallocchio F, Zanella M, Bregoli L, Biancotto G, Ricci A. Antibacterial activity of silver nanoparticles: Sensitivity of different Salmonella serovars. Front Microbiol, 2014; 5:227.

Luyen BT, Tai BH, Thao NP, Yang SY, Cuong NM, Kwon YI, Jang HD, Kim YH. A new phenylpropanoid and an alkylglycoside from Piper retrofractum leaves with their antioxidant and $\alpha$-glucosidase inhibitory activity. Bioorg Med Chem Lett, 2014; 24(17):4120-4.

Makarov VV, Love AJ, Sinitsyna OV, Makarova SS, Yaminsky IV, Taliansky ME, Kalinina NO. "Green" nanotechnologies: synthesis of metal nanoparticles using plants. Acta Naturae (Англоязычная Версия), 2014; 6(1):35-44 .

Manosi D, Avijit B, Sreya D, Sanjoy S, DN M, Jayram H. Comparative pharmacognostical, phytochemical and HPTLC study of some common medicinal Piper species. Int J Res Ayurveda Pharm, 2016; 7(6):19-24.

Masum MMI, Siddiqa MM, Ali KA, Zhang Y, Abdallah Y, Ibrahim E, Qiu W, Yan C, Li B. Biogenic synthesis of silver nanoparticles using Phyllanthus emblica fruit extract and its inhibitory action against the pathogen Acidovorax oryzae strain RS-2 of rice bacterial brown stripe. Front Microbiol, 2019; 10:820.

Muharini R, Liu Z, Lin W, Proksch P. New amides from the fruits of Piper retrofractum. Tetrahedron Letters, 2015; 56(19):2521-5.

Pandey S, Goswami GK, Nanda KK. Green synthesis of biopolymer-silver nanoparticle nanocomposite: an optical sensor for ammonia detection. Int J Biol Macromol, 2012; 51(4):583-9.

Panphut W, Budsabun T, Sangsuriya P. In vitro antimicrobial activity of Piper retrofractum fruit extracts against microbial pathogens causing infections in human and animals. Int J Microbiol, 2020; 2020: 5638961.

Pirtarighat S, Ghannadnia M, Baghshahi S. Green synthesis of silver nanoparticles using the plant extract of Salvia spinosa grown in vitro and their antibacterial activity assessment. J Nanostruc Chem, 2019; 9(1):1-9.

Rajeshkumar S, Malarkodi C. In vitro antibacterial activity and mechanism of silver nanoparticles against foodborne pathogens. Bioinorg Chem Appl, 2014; 2014:581890.

Rani R, Sharma D, Chaturvedi M, Yadav JP. Green synthesis of silver nanoparticles using Tridax procumbens: their characterization, antioxidant and antibacterial activity against MDR and reference bacterial strains. Chem Papers, 2019; 1-14.

Rautela A, Rani J, Das MD. Green synthesis of silver nanoparticles from Tectona grandis seeds extract: characterization and mechanism of antimicrobial action on different microorganisms. J Anal Sci Technol, 2019; 10(1):1-10.

Shah M, Fawcett D, Sharma S, Tripathy SK, Poinern GE. Green synthesis of metallic nanoparticles via biological entities. Materials, 2015; 8(11):7278-308.

Shahzad A, Saeed H, Iqtedar M, Hussain SZ, Kaleem A, Abdullah R, Sharif S, Naz S, Saleem F, Aihetasham A, Chaudhary A. Size-controlled production of silver nanoparticles by Aspergillus fumigatus BTCB10: likely antibacterial and cytotoxic effects. J Nanomater, 2019; 2019: 5168698.

Sooraj MP, Nair AS, Vineetha D. Sunlight-mediated green synthesis of silver nanoparticles using Sida retusa leaf extract and assessment of its antimicrobial and catalytic activities. Chem Papers, 2020; 75(1):1-13.

Srirangam GM, Rao KP. Synthesis and charcterization of silver nanoparticles from the leaf extract of Malachra capitata (L.). Rasay J Chem, 2017; 10(1):46-53. 
Sumitomo S, Koizumi H, Uddin MA, Kato Y. Comparison of dispersion behavior of agglomerated particles in liquid between ultrasonic irradiation and mechanical stirring. Ultraso Sonochem, 2018; 40:822-31.

Tang R, Zhang YQ, Hu DB, Yang XF, Yang J, San MM, Oo TN, Kong Y, Wang YH. New amides and phenylpropanoid glucosides from the fruits of Piper retrofractum. Nat Prod Bioprospect, 2019; 9(3):231-41.

Tripathy S, Rademan S, Matsabisa MG. Effects of silver nanoparticle from Dicoma anomala Sond. Root extract on MCF-7 cancer cell line and NF54 parasite strain: an in vitro study. Biol Trace Element Res, 2019; 195(1):1-13.

Veerasamy R, Xin TZ, Gunasagaran S, Xiang TF, Yang EF, Jeyakumar N, Dhanaraj SA. Biosynthesis of silver nanoparticles using mangosteen leaf extract and evaluation of their antimicrobial activities. J Saudi Chem Soc, 2011; 15(2):113-20.

Wang X, Andrews L. Infrared spectra and structures of the coinage metal dihydroxide molecules. Inorga Chem, 2005; 44(24):9076-83.

Yasir M, Singh J, Tripathi MK, Singh P, Shrivastava R. Green synthesis of silver nanoparticles using leaf extract of common arrowhead houseplant and its anticandidal activity. Pharmacogn Mag, 2017; 13(Suppl 4):S840

Yin IX, Zhang J, Zhao IS, Mei ML, Li Q, Chu CH. The antibacterial mechanism of silver nanoparticles and its application in dentistry. Int J Nanomed, 2020; 15:2555.
Qing Y, Cheng L, Li R, Liu G, Zhang Y, Tang X, Wang J, Liu $\mathrm{H}$, Qin Y. Potential antibacterial mechanism of silver nanoparticles and the optimization of orthopedic implants by advanced modification technologies Int J Nanomedicine, 2018; 13:3311.

Yusuf M. Silver nanoparticles: synthesis and applications. In: Martínez LMT, Kharissova OV, and Kharisov BI, ed(s). Handbook of ecomaterials, Springer, Zürich, Switzerland, 2343 p, 2019.

How to cite this article:

Amaliyah S, Sabarudin A, Masruri M, Sumitro SB. Characterization and antibacterial application of biosynthesized silver nanoparticles using Piper retrofractum Vahl fruit extract as bioreductor. J Appl Pharm Sci, 2022; 12(03):103-114. 